\title{
Importanța examenului ecografic în diagnosticul şi tratamentul afecțiunilor musculo-scheletale din hemofilia A
}

Adriana Diaconu1, Oana Rizea, Horațiu Vultur1
1Clinica de Pediatrie, Institutul Clinic „Fundeni“, Universitatea de Medicină şi Farmacie
"Carol Davila“, Bucureşti , România
${ }^{2}$ Clinica de Radiologie, Institutul Clinic „Fundeni“, Universitatea de Medicină şi Farmacie
"Carol Davila“, Bucureşti, România

\begin{abstract}
REZUMAT
În hemofilia A, definită prin deficitul de factor VIII al coagulării, pot apare sângerări cu diferite localizări, în special la nivel musculo-articular. Ecografia joacă un rol foarte important în monitorizarea și modularea tratamentului substitutiv cu factor VIII al acestor pacienți confirmând momentul obținerii remisiunii complete clinico-imagistice.
\end{abstract}

Cuvinte cheie: hemofilie A, ecografie, afectare musculo-scheletală

\section{INTRODUCERE}

Hemofilia congenitală A este o tulburare de coagulare, cu transmitere X-lincată, caracterizată prin deficitul de factor VIII. Gena care comandă sinteza factorilor de coagulare este situată pe cromozomul $\mathrm{X}$, astfel încât tabloul clinic apare doar la pacienții de sex masculin şi este reprezentat de sângerări cu localizări diferite: cutanate/subcutanate, mucoase, musculare, spații celulare, viscerale, articulații (hemartroze) (1).

Valoarea normală a concentrației de F VIII variază între 50-150\%. Astfel, gradele de severitate ale hemofiliei sunt definite în funcție de deficitul $\mathrm{F}$ VIII:

- Forma severă (F VIII < 1\%);

- Forma medie (F VIII: 1-5\%);

- Forma usoară (F VIII: 5-40\%).

Hemartrozele reprezintă cea mai frecventă sângerare (70-80\% din cazuri) şi se caracterizează prin urmatoarele: afectează predominant articulațiile mari (genunchi, coate, gleznă, pumn, şold), pot fi provocate de un traumatism minor (de exemplu un drum mai lung) şi au tendință la recidivă (1). În absența tratamentului substitutiv, evoluția este de la hemartroză pură la artropatia hemofilică şi ulterior la anchiloza articulară. Se pot produce alterări ale sinovialei şi cartilajului osos, cu diferite grade de reducere a mobilității articulare (2).

Tratamentul substitutiv constă în administrarea intravenoasă a unor concentrate de F VIII obţinute din plasmă umană (concentrate derivate plasmatic) sau produse genetic în laborator (concentrate recombinate).

Obiectivul principal al tratamentului hemostatic în hemofilie este acela de a preveni hemoragiile (tratament profilactic continuu individualizat) sau de a le trata cât mai precoce şi eficient cu doze, ritm de administrare şi durată adaptate fiecărui caz (terapia «on-demand»).

Debutul acestei afecțiuni hematologice este precoce în cazul formelor severe de boală (F VIII < $1 \%$ ), la majoritatea pacienților chiar în primul an de viată, atunci când copilul începe sa meargă. Astfel, pentru copiii cu fenotip sever, se recomandă pe termen lung substituția profilactică personalizată cu scopul de a menţine permanent o concentrație plasmatică a F VIII peste 1\% (valoare minimă pentru a preveni sângerările spontane) $(3,4)$. 
Profilaxia primară trebuie iniţiată cât mai rapid după diagnostic, înainte sau imediat după primul episod de hemartroza, şi trebuie continuată cel puțin pe toată perioada copilăriei şi adolescenței. Stabilirea schemei terapeutice (doza şi frecvența acestora) va depinde de vârsta pacientului, fenotipul sângerărilor, intensitatea activităților fizice, complianța la tratament a pacientului şi a aparţinătorilor acestuia (parinţii). Chiar şi în cazul unei profilaxii atent monitorizate, se pot produce hemoragii recurente intraarticulare minore, asimptomatice, care în timp vor determina modificări de tip artropatie cronică $(3,5)$.

În momentul când apare o hemartroză, se asociază terapiei hemostatice şi alte măsuri generale de tipul repausului articular, aplicații reci locale, anumite proceduri de fizioterapie, în cazuri foarte rare de acumulări sanguine masive - puncția aspirat intraarticular, iar ulterior recuperarea medicală (2).

Tratamentul substitutiv "on-demand" trebuie administrat optim în primele 2 ore de la debutul sângerării clinic evidente şi va fi individualizat în funcție de localizarea acesteia, concentrația plasmatică a F VIII necesară hemostazei şi riscul complicațiilor severe.

În absenţa unei hemostaze eficiente şi rapide, episoadele hemoragice repetate vor evolua de la stadiul de hemartroză acută la cel de hemartroză subacută şi în final la cel de artropatie cronică asociind pierderea semnificativă a funcției musculare şi retracții tendinoase ireversibile datorită poziției vicioase antalgice (3).

De aceea, este foarte importantă o evaluare musculo-scheletală periodică sau atunci când se produce o sângerare, examinarea clinică fiind completată de o tehnică imagistică (radiografie, ultrasonografie, rezonanță magnetică nucleară - cu indicație punctuală pentru fiecare caz) $(3,4)$.

Ecografia este o metodă eficientă, rapidă şi accesibilă de confirmare şi de modulare a tratamentului sângerărilor musculo-scheletale în hemofilie. (6-8). De asemenea, numeroase studii au demonstrat faptul că ecografia este foarte utilă în depistarea sângerarilor articulare asimptomatice $(9,10)$. Asa cum reiese şi din studiul nostru, diagnosticul precoce şi monitorizarea remisiunii episoadelor de sângerare acută atât clinic, cât şi ecografic, influențează terapia substitutivă, în vederea minimalizării modificărilor patologice cu potențial evolutiv cronic muscular şi articular sever (pseudotumori şi anchiloze articulare) $(2,6,8,11)$.

Vom prezenta în continuare rezultatele studiului nostru, de tip prospectiv, pe o perioadă de 2 ani (1 ianuarie 2012 - 31 decembrie 2013), al cărui scop a fost de precizare a rolului ecografiei în diagnosticul şi tratamentul afecțiunilor musculo-scheletale la pacienții diagnosticați cu hemofilie A formă severă şi medie internați în Clinica de Pediatrie a Institutului Clinic Fundeni.

\section{OBIECTIVE}

Obiectivele acestui studiu au fost reprezentate de:

1. confirmarea imagistică a afectării musculoscheletate decelate clinic;

2. monitorizarea eficienței tratamentului şi modularea acestuia;

3. corelația dintre remisiunea clinică şi cea imagistică.

\section{METODĂ}

Metoda a constat în efectuarea de ecografii seriate la 23 de pacienți cu hemofilie A formă severă şi medie, urmărindu-se: prezența sângerării intra-articular sau muscular, dimensiunile acesteia, evoluția sub tratament, momentul obținerii remisiunii complete clinico-imagistice.

Criteriile de includere în studiu:

- băieți cu vârstă 1-18 ani diagnosticaţi cu hemofilie A forma severă (factor VIII $<1 \%$ ) şi medie (factor VIII 1-5\%);

- debutul sângerării în urmă cu maxim 48 de ore anterior internării;

- localizare articulară sau musculară a sângerării;

- complianța la tratament prin spitalizare completă.

Datele au fost prelucrate din foile de observație ale pacienților.

\section{REZULTATE}

Rezultatele ecografiilor au descris următoarele aspecte: hematoame musculare - 3 pacienți $(12,9 \%)$, hemartroze cu îngroşarea sinovialei - 12 pacienți $(52,6 \%)$, hemartroze cu proliferarea sinovialei -8 pacienți $(35,5 \%)$. Examinările ecografice de la internare au confirmat diagnosticul clinic suspicionat de hemartroză sau hematom muscular la 23 pacienți $(100 \%)$ din lotul studiat. 20 pacienți $(86,9 \%)$ au necesitat continuarea tratamentului substitutiv în medie 2 zile după rezoluția clinică până la obținerea rezoluției imagistice. S-a constatat remisiune completă concomitentă clinico-imagistică la 1 singur pacient (4,3\%). Pentru 2 pacienți $(8,6 \%)$ atât diagnosticul, cât şi monitorizarea până la rezoluție au fost confirmate doar ecografic. 
TABELUL 1. Vârsta medie a pacienților a fost de 10,65

\begin{tabular}{|c|c|c|c|c|c|c|c|}
\hline Pacient & $\begin{array}{c}\text { Localizare } \\
\text { Hematom muscular }\end{array}$ & $\begin{array}{l}\text { Localizare } \\
\text { Hemartroză }\end{array}$ & Sinovială & $\begin{array}{l}\text { Diagnostic } \\
\text { clinic }\end{array}$ & $\begin{array}{c}\text { Confirmare } \\
\text { ecografică }\end{array}$ & $\begin{array}{c}\text { Zile rezoluție } \\
\text { clinică }\end{array}$ & $\begin{array}{c}\text { Zile rezoluție } \\
\text { imagistică }\end{array}$ \\
\hline 1 & - & Genunchi drept & Proliferare & $\mathrm{Da}$ & $\mathrm{Da}$ & 4 & 6 \\
\hline 2 & - & Genunchi drept & Proliferare & $\mathrm{Da}$ & $\mathrm{Da}$ & 5 & 8 \\
\hline 3 & - & Gleznă dreaptă & Proliferare & $\mathrm{Da}$ & $\mathrm{Da}$ & 3 & 3 \\
\hline 4 & Iliopsoas & - & - & $\mathrm{Da}$ & $\mathrm{Da}$ & 13 & 21 \\
\hline 5 & & Cot stâng & Subţiere & $\mathrm{Da}$ & $\mathrm{Da}$ & 3 & 4 \\
\hline 6 & - & Gleznă stângă & Subţiere & $\mathrm{Nu}$ & $\mathrm{Da}$ & - & 3 \\
\hline 7 & - & $\begin{array}{c}\text { Fosă poplitee } \\
\text { dreaptă }\end{array}$ & Proliferare & $\mathrm{Da}$ & $\mathrm{Da}$ & 6 & 8 \\
\hline 8 & - & Genunchi stâng & Proliferare & $\mathrm{Da}$ & $\mathrm{Da}$ & 4 & 7 \\
\hline 9 & Femural stâng & - & - & $\mathrm{Da}$ & $\mathrm{Da}$ & 8 & 10 \\
\hline 10 & - & Genunchi drept & Proliferare & $\mathrm{Da}$ & $\mathrm{Da}$ & 5 & 6 \\
\hline 11 & - & Gleznă dreaptă & Subţiere & $\mathrm{Nu}$ & $\mathrm{Da}$ & - & 2 \\
\hline 12 & $\begin{array}{l}\text { Gastrocnemian } \\
\text { medial }\end{array}$ & - & - & $\mathrm{Da}$ & $\mathrm{Da}$ & 7 & 9 \\
\hline 13 & - & Gleznă dreaptă & Subţiere & $\mathrm{Da}$ & $\mathrm{Da}$ & 3 & 4 \\
\hline 14 & - & $\begin{array}{l}\text { Fosă poplitee } \\
\text { stângă }\end{array}$ & Proliferare & $\mathrm{Da}$ & $\mathrm{Da}$ & 5 & 6 \\
\hline 15 & - & Cot stâng & Subţiere & $\mathrm{Da}$ & $\mathrm{Da}$ & 3 & 4 \\
\hline 16 & - & Gleznă dreaptă & Subţiere & $\mathrm{Da}$ & $\mathrm{Da}$ & 4 & 6 \\
\hline 17 & - & Gleznă stângă & Subţiere & $\mathrm{Da}$ & $\mathrm{Da}$ & 4 & 5 \\
\hline 18 & - & Cot drept & Subţiere & $\mathrm{Da}$ & $\mathrm{Da}$ & 4 & 6 \\
\hline 19 & - & Cot drept & Subţiere & $\mathrm{Da}$ & $\mathrm{Da}$ & 3 & 4 \\
\hline 20 & - & Cot stâng & Subţiere & $\mathrm{Da}$ & $\mathrm{Da}$ & 5 & 7 \\
\hline 21 & - & Gleznă stângă & Subţiere & $\mathrm{Da}$ & $\mathrm{Da}$ & 2 & 3 \\
\hline 22 & - & Gleznă dreaptă & Subţiere & $\mathrm{Da}$ & $\mathrm{Da}$ & 2 & 4 \\
\hline 23 & - & Genunchi drept & Proliferare & $\mathrm{Da}$ & $\mathrm{Da}$ & 4 & 6 \\
\hline
\end{tabular}

\section{DISCUTुII}

Articulațiile reprezintă principala localizare (> 80-90\% din cazuri) a sângerărilor în hemofilia severă sau moderată, cu sau fară inhibitori, indiferent de vârsta pacientului, fapt constatat şi în studiul de față (20 de pacienți cu hemartroze $=86,9 \%$ din totalul pacienților din lotul de studiu) $(12,13)$.

În absența unui tratament hemostatic adecvat, evoluția este de la hemartroză pură acută la artropatie cronică, cu apariţia anchilozelor şi a deformărilor articulare, dureroase, care determină instalarea dizabilităților, reducând astfel foarte mult calitatea vieții pacienților (pacienții nu se mai pot îngriji singuri). Sunt afectate în ordine cronologică (pe rând) sinoviala, cartilajul şi osul, articulaţia prezentând un aspect degenerativ.

Tratamentul profilactic sau curativ substitutiv cu concentrate de factori de coagulare are ca scop prevenirea procesului progresiv ireversibil de degradare articulară (cele mai frecvente articulații țintă fiind genunchii, coatele şi gleznele).

Fierul eliberat din hemoglobină şi depozitat sub formă de hemosiderină, ca urmare a hemoragiilor intraarticulare repetate, asimptomatice sau clinic evidente, determină o reacție cronică inflamatorie şi degenerativă, precum şi de neo-angiogeneză, rezultând proliferare cronică a sinovialei (prezentă la $35,5 \%$ dintre pacienții aflați în studiu) şi ulterior distrugerea cartilajului şi a osului (nu a fost cazul la nici unul din pacienții din studiu) (12-16).

Aceste procese sunt mediate de citokine proinflamatorii (IL-1 $\beta$, IL-1 $\alpha$, IL-6) şi factorul de necroză tumorală TNF- $\alpha$, a căror expresie este activată de prezența fierului intraarticular $(13,17)$.

Sângerările musculare reprezintă a 2-a localizare ca incidență (10-23\%), fapt confirmat şi de studiul de față $(12,9 \%=3$ pacienți diagnosticați cu hematoame musculare). La fel ca pentru hemartroze, se impune un tratament hemostatic adecvat, profilactic sau curativ, astfel încât să se evite apariția complicațiilor severe, ca sindromul de compartiment, neuropatia, infecțiile, formarea pseudotumorilor, miozita osifiantă (18).

De aceea este foarte important să prevenim hemartrozele / hematoamele sau, atunci când acestea se produc, să obținem cât mai rapid o remitere completă a sângelui intraarticular / intramuscular. 
Acest lucru se poate realiza doar printr-un tratament hemostatic adecvat care va fỉ administrat până când aspectul ecografic relevă dispariția completă a sângelui, care poate urma la cateva zile dupa rezoluția clinică (la 86,9\% dintre pacienții evaluați rezoluția imagistică s-a realizat după o medie de 2 zile fată de cea clinică; la doar 1 pacient $=4,3 \%$ a existat concordantă clinico-imagistică). Ecografia are 2 roluri: primul este de confirmare a colecției sanguine intraarticular/intramuscular (la 100\% din cazurile studiate); cel de-al doilea este de apreciere a integrității structurale a articulației/muschiului (19-22).

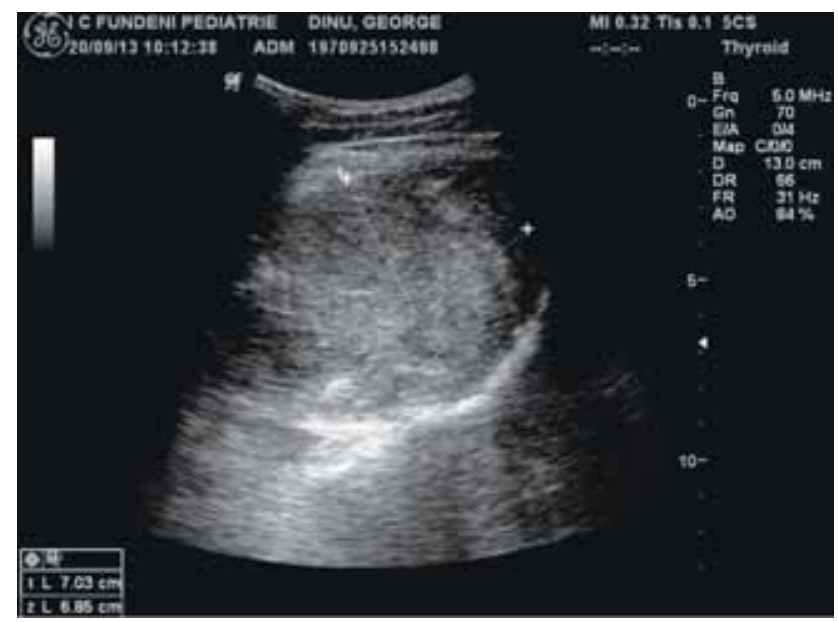

FIGURA 1. Acumulare predominant hiperecogenă (componentă intens hiperecogenă corespunde hemoragiei acute, în desfăşurare la momentul examinării) localizată intramuscular, la nivelul compartimentului muscular ilio-psoic de partea stângă la un copil cunoscut cu hemofilie.

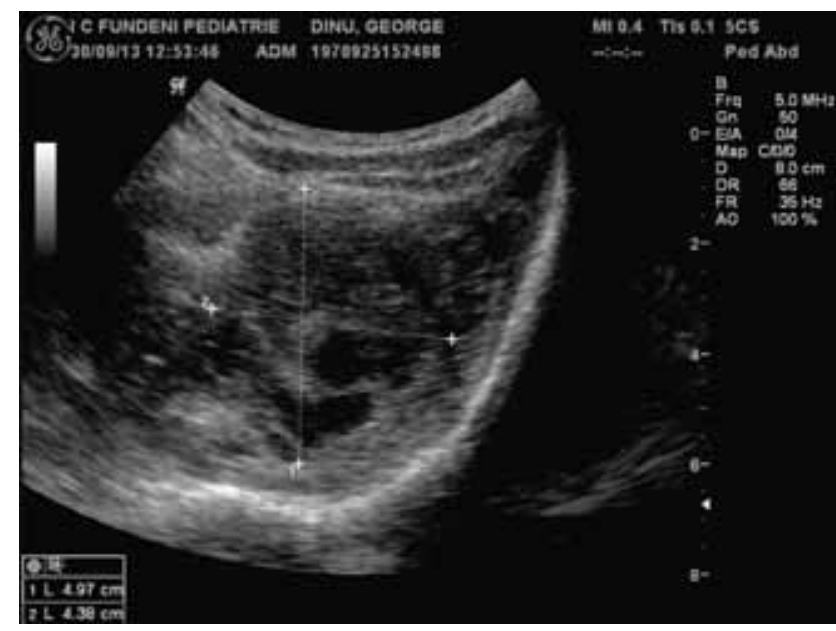

FIGURA 2. În evoluție, la acelaşi pacient corespunzând pozei 1, hematomul îşi reduce dimensiunile având un aspect heterogen (izo/discret hipoecogen periferic cu arie hipoecogen-transonică centrală corespunzând sângelui degradat).

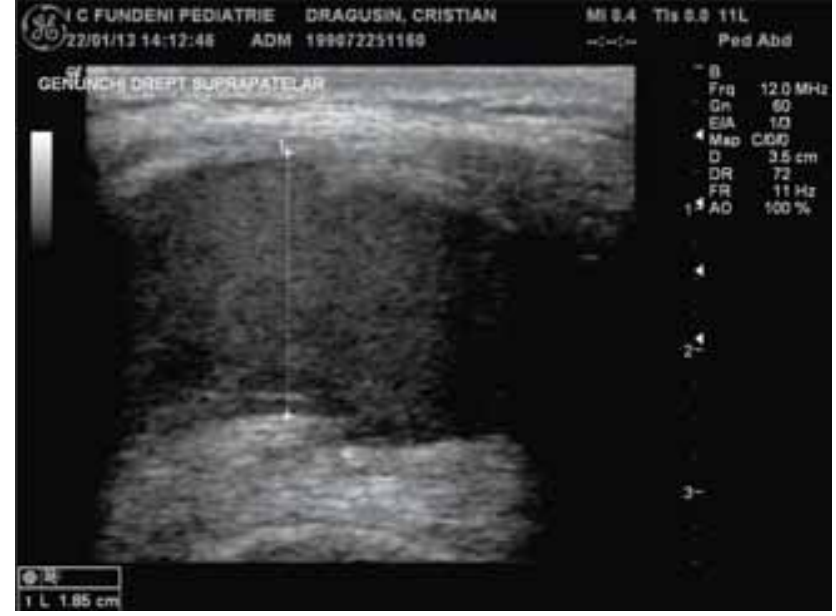

FIGURA 3. Hematom acut intraarticular (genunchi drept) la un copil cunoscut cu hemofilie A formă severă şi inhibitori, cu sângerări recente intraarticulare

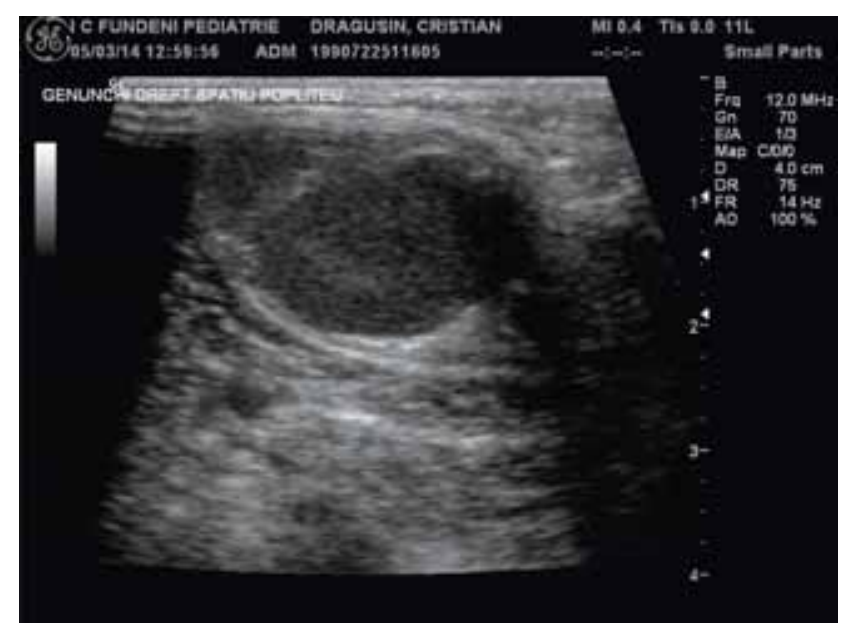

FIGURA 4. Acumulare polilobată, ovalară, bine delimitată (aparent incapsulată), heterogenă prin prezența de septuri intralezionale compatibilă cu hematom acut, localizată în părțile moi ale spațiului popliteu inferior drept comunicând cu spațiul articular, la acelaşi pacient cu hemofilie A formă severă şi inhibitori.

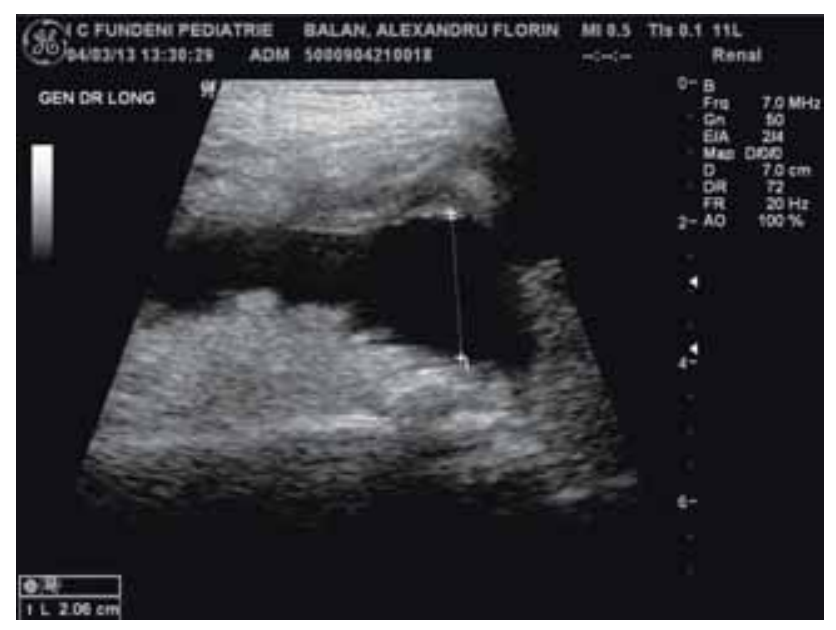

FIGURA 5 


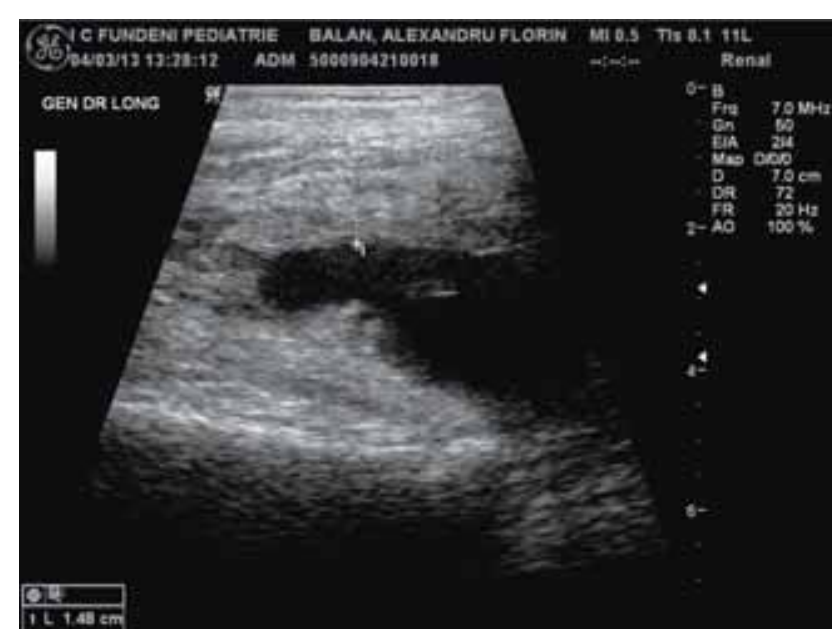

FIGURA 5 şi 6. Acumulare transsonică (hematică restantă) la nivelul articulației genunchiului drept asociind importantă proliferare a sinovialei la acest nivel, la un copil cu hemofilie A formă severă

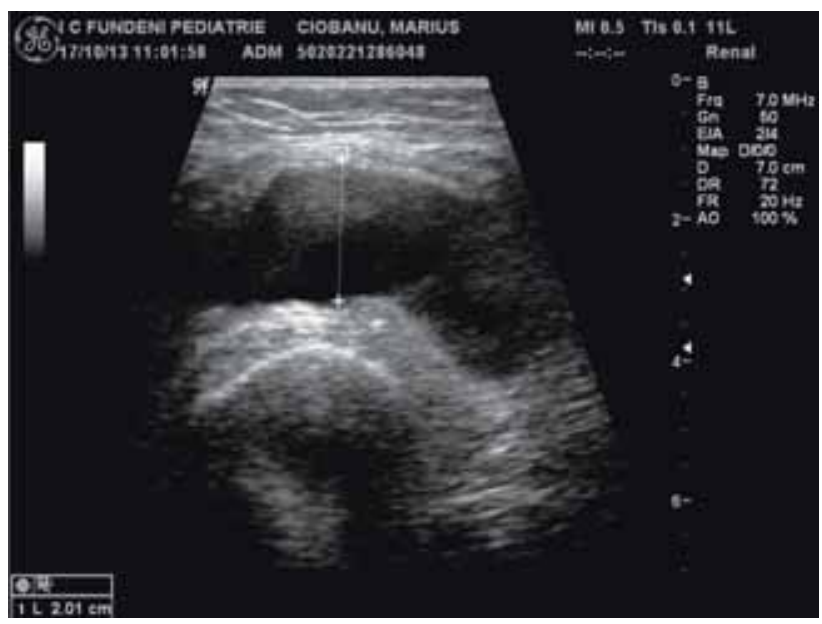

FIGURA 7. Acumulare hiperecogenă, relativ omogenă, localizată la nivelul articulației genunchiului drept, predominant în recesul suprapatelar, compatibil cu hematom în curs de degradare la un copil cunoscut cu hemofilie A formă severă.

\section{CONCLUZII}

Minimalizarea afectării cronice cu modificări degenerative ireversibile ale sistemului musculoscheletal în hemofilia severă şi medie reprezintă principalul obiectiv al îngrijirii pacienților cu această patologie.

Identificarea alterărilor precoce articulare şi prevenirea evolutivă a acestora se pot realiza doar printr-o monitorizare complexă periodică în centre comprehensive specializate. Examinarea ecografică confirmă existența hemoragiilor localizate sau difuze şi furnizează informații precise asupra statusului articular şi compartimentului muscular, pornind de la descrierea unor aspecte sugestive de afectare precoce la aceste nivele prin sângerări asimptomatice care nu pot fi obiectivate clinic şi până la alterări importante cu distrugeri ale structurilor componente (sinovială, cartilaj, os, fibre musculare).

Tehnica ecografică este rapidă, accesibilă şi puțin costisitoare, având un rol determinant în adoptarea unei atitudini terapeutice optime, personalizate a fiecărui episod hemoragic. Astfel, prin evitarea progresiei degenerative musculo-scheletale, secundară hemoragiilor, se îmbunătățeşte semnificativ calitatea vieții pacienților cu hemofilie.

Conflict of interest: none declared Financial support: none declared 